\title{
Angiotensin-converting Enzyme 2 Specific Cell Subset Identification in Oral Tissues: A Need of the Hour in COVID-19 Research
}

\author{
Gargi S Sarode ${ }^{1}$, Sachin C Sarode ${ }^{2}$, Amol R Gadbail ${ }^{3}$, Shailesh Gondivkar ${ }^{4}$, Nilesh K Sharma ${ }^{5}$, Shankargouda Patil ${ }^{6}$
}

The Journal of Contemporary Dental Practice (2020): 10.5005/jp-journals-10024-2943

It is well known that angiotensin-converting enzyme 2 (ACE2) is an important host factor responsible for the attachment of severe acute respiratory syndrome coronavirus clad 2 (SARS-CoV-2). ACE2 has been predominantly reported to be present in lungs and nasal mucosa, which is the most common site for the initiation of COVID-19.' Apart from lungs, ACE2 is also expressed in heart, blood vessels, kidneys, brain, intestines, etc. ${ }^{2}$ Recently various locations of the oral cavity have been found to be associated with differential expression of ACE2 protein, with the tongue being the most common site. ${ }^{3}$ Moreover, the salivary glands have also been regarded as a potential source of SARS-CoV-2 infection due to the presence of the ACE2 receptor. ${ }^{4}$ However, till date there is no strong scientific evidence that has proved the existence and interaction of ACE2 protein and spike receptor of SARS-CoV-2 on oral mucosal and salivary gland epithelial cells.

Oral mucosa is covered by stratified squamous epithelium (keratinized, nonkeratinized, and specialized mucosa) and is composed of different strata of cells, which include basal, suprabasal, spinous, granular, and superficial layers. Besides, nonkeratinocytes such as melanocytes, Merkel cells, and Langerhans cells are common residents of the oral mucosa. The tongue is regarded as a specialized mucosa of the oral cavity and is composed of taste buds. Taste buds are made up of taste receptor cells, supporting cells, and basal cells. On a similar ground, the salivary gland is composed of structurally and functionally different cell types such as acinar (serous and mucous), myoepithelial, ductal (intercalated, striated, and excretory), oncocytes, goblet, and stromal (fibroblasts, defense, etc.) cells. ${ }^{5}$ With so many variations in the cell types that are functionally and structurally different, it becomes necessary to identify the exact cell subset that expresses ACE2 protein.

We speculate that not all but only a few cell subsets of oral mucosa and salivary glands harbor the expression of ACE2 protein and, hence, form the targets for the spike receptor of SARS-CoV-2. This is just like the recently identified ACE2 positive cell subsets such as type II pneumocytes in the lung, absorptive enterocytes within the gut, and goblet secretory cells of the nasal mucosa. ${ }^{6}$ Goblet cells are also a part of salivary gland cellular architecture and are predominantly located at the entrance of the excretory duct into the oral cavity. ${ }^{7}$ Thus, due to the structural and functional similarity, goblet cells can form the cell subset for the Spike receptor of SARS-CoV-2. Another possible candidate for the presence of ACE2 protein could be Langerhans cells located in the stratified squamous epithelium, which are regarded as antigen-presenting cells. At other body locations such as lungs, Langerhans-type dendritic cells are known to harbor ACE2 protein on their surface. Similarly, probing
1,2Department of Oral Pathology and Microbiology, Dr DY Patil Dental College and Hospital, Dr DY Patil Vidyapeeth, Pimpri, Pune, Maharashtra, India

${ }^{3}$ Department of Dentistry, Indira Gandhi Government Medical College and Hospital, Nagpur, Maharashtra, India

${ }^{4}$ Department of Oral Medicine and Radiology, Government Dental College and Hospital, Nagpur, Maharashtra, India

${ }^{5}$ Cancer and Translational Research Lab, Dr DY Patil Biotechnology and Bioinformatics Institute, Dr DY Patil Vidyapeeth, Pune, Maharashtra, India

${ }^{6}$ Department of Maxillofacial Surgery and Diagnostic Sciences, Division of Oral Pathology, College of Dentistry, Jazan University, Jazan, Saudi Arabia

Corresponding Author: Sachin C Sarode, Department of Oral Pathology and Microbiology, Dr DY Patil Dental College and Hospital, Dr DY Patil Vidyapeeth, Pimpri, Pune, Maharashtra, India, Phone: +91 9922491465, e-mail: drsachinsarode@gmail.com

How to cite this article: Sarode GS, Sarode SC, Gadbail AR, et al. Angiotensin-converting Enzyme 2 Specific Cell Subset Identification in Oral Tissues: A Need of the Hour in COVID-19 Research. J Contemp Dent Pract 2020;21(12):1305-1306.

Source of support: Nil

Conflict of interest: None

into the other tissue types is the need of the hour to identify the exact cell subset in oral cavity. Furthermore, authentication of ACE2 in the salivary gland and in the oral epithelial cells will also help in the development and authentication of salivary diagnostics for COVID-19. ${ }^{8}$

We recommend studies on the immunohistochemical expression of various locations of the oral cavity to provide baseline data for establishing the proof of concept. Further authorization of the ACE2 expression can only be achieved with highly specific parallel single-cell RNA sequencing with subsequent confirmation in animal and human models. As proposed recently, the results of immunohistochemistry studies can be translated into the development of an ACE2-based rapid diagnostic kit for the detection of COVID-19 using exfoliative cytology samples. ${ }^{9}$

It has been speculated that certain oral pathologies cause a high expression of ACE2 due to the action of interferon-stimulated gene expression. ${ }^{10}$ Such pathologies include lichen planus, aphthous ulcers, candidiasis, and herpes infections. Logically, such patients are highly susceptible to COVID-19 and should take

(c) Jaypee Brothers Medical Publishers. 2020 Open Access This article is distributed under the terms of the Creative Commons Attribution 4.0 International License (https://creativecommons.org/licenses/by-nc/4.0/), which permits unrestricted use, distribution, and non-commercial reproduction in any medium, provided you give appropriate credit to the original author(s) and the source, provide a link to the Creative Commons license, and indicate if changes were made. The Creative Commons Public Domain Dedication waiver (http://creativecommons.org/publicdomain/zero/1.0/) applies to the data made available in this article, unless otherwise stated. 
utmost precautions. Due to fibrosis in the submucosal tissue, ACE2 expression and consequently the nature of susceptibility to COVID-19 in oral submucous fibrosis is highly unpredictable. ${ }^{11,12}$ In this regard, immunohistochemical and RNA-sequencing of ACE2 molecule in these pathologies will help in strengthening the proposed contention.

Besides expression at RNA and protein levels, a speculation on the role of epigenetic regulation of ACE2 expression by various factors, including the role of the microbiome within the oral cavity tissue microenvironment, seems feasible. Such understanding may help to reveal the basis of ACE2-specific cell subset identification in the oral tissues. In addition to identification, quantification of the ACE2 protein positive cells is the need of the hour to better understand the pathogenesis of COVID-19.

\section{References}

1. Hoffmann M, Kleine-Weber H, Schroeder S, et al. SARS-CoV-2 cell entry depends on ACE2 and TMPRSS2 and is blocked by a clinically proven protease inhibitor. Cell 2020;181(2):271-280.e8. DOI: 10.1016/j. cell.2020.02.052.

2. Hamming I, Timens $W$, Bulthuis ML, et al. Tissue distribution of ACE2 protein, the functional receptor for SARS coronavirus. A first step in understanding SARS pathogenesis. J Pathol 2004;203(2):631-637. DOI: 10.1002/path.1570.

3. Xu H, Zhong L, Deng J, et al. High expression of ACE2 receptor of 2019nCoV on the epithelial cells of oral mucosa. Int J Oral Sci 2020;12(1):8. DOI: 10.1038/s41368-020-0074-x.
4. Pascolo L, Zupin L, Melato M, et al. TMPRSS2 and ACE2 coexpression in SARS-CoV-2 salivary glands infection. J Dent Res 2020(10):22034520933589 10.1177/0022034520933589.

5. Porcheri C, Mitsiadis TA. Physiology, pathology and regeneration of salivary glands. Cells 2019;8(9):976. DOI: 10.3390/cells8090976.

6. Ziegler CGK, Allon SJ, Nyquist SK, et al. SARS-CoV-2 receptor ACE2 is an interferon-stimulated gene in human airway epithelial cells and is detected in specific cell subsets across tissues. Cell 2020;181(5):10161035.e19. DOI: 10.1016/j.cell.2020.04.035.

7. Kutta H, May J, Jaehne M, et al. Antimicrobial defence mechanisms of the human parotid duct. J Anat 2006;208(5):609-619. DOI: 10.1111/j.1469-7580.2006.00567.x.

8. Sarode SC, Sarode GS, Gopalakrishnan D, et al. Critical appraisal on salivary diagnostic for COVID-19. Oral Oncol 2020;108:104926. DOI: 10.1016/j.oraloncology.2020.104926.

9. Mhaske S, Yuwanati M, Mhaske A, et al. Perspective on oral exfoliative cytology and COVID-19. Oral Oncol 2020;107:104858. DOI: 10.1016/j. oraloncology.2020.104858.

10. Sarode GS, Sarode SC, Gadbail AR, et al. Patients with interferon expressing oral pathologies are susceptible to COVID-19 infection. Med Hypotheses 2020;144:110179. DOI: 10.1016/j.mehy.2020. 110179.

11. Sarode SC, Sarode GS, Gondivkar S, et al. Oral submucous fibrosis and COVID-19: perspective on comorbidity. Oral Oncol 2020;107:104811. DOI: 10.1016/j.oraloncology.2020.104811.

12. Varadarajan S, Balaji TM, Sarode SC, et al. EMMPRIN/BASIGIN as a biological modulator of oral cancer and COVID-19 interaction: Novel propositions. Med Hypotheses 2020;143:110089. DOI: 10.1016/j. mehy.2020.110089. 